\title{
TAVI and risk scores: Looking back while moving forward
}

\author{
Federico Conrotto, Francesco Bruno, Fabrizio D’Ascenzo \\ Division of Cardiology, Cardiovascular and Thoracic Department, University of Turin, Città della Salute e della Scienza, Turin, Italy \\ Related article \\ by Özdemir et al. \\ see p. 1215
}

\author{
Correspondence to: \\ Federico Conrotto, MD, \\ Cardiovascular and Thoracic \\ Department, Division of \\ Cardiology, Città della Salute \\ e della Scienza, \\ Corso Bramante $88 / 90$ \\ 10126, Torino, Italy, \\ phone: +390116336023, \\ e-mail: \\ federico.conrotto@gmail.com \\ Copyright by the Author(s), 2021 \\ Kardiol Pol. 2021; \\ 79 (11): 1193-1194. \\ DOI: 10.33963/KP.a2021.0155 \\ Received: \\ November 7, 2021 \\ Revision accepted: \\ November 8, 2021 \\ Published online: \\ November 25, 2021
}

According to the latest European guidelines, transcatheter aortic valve implantation (TAVI) has become the treatment of choice in patients with severe symptomatic aortic stenosis (AS) older than 75 years. These guidelines broaden the indications for TAVI to include intermediate and low-risk patients due to the superimposable short and long-term results compared to surgery [1-3].

Historically, risk scores are decision-making tools designed to estimate procedural outcomes both in trials and in real-world experience [4]. In the TAVI field, risk scores have been mostly used to guide the choice between TAVI and surgical aortic valve replacement (SAVR). The Society of Thoracic Surgeons predicted risk for mortality (STS) and the logistic European System for Cardiac Operative Risk Evaluation (EuroSCORE I and II) are the most common scores used in North America and Europe, respectively $[5,6]$. However, they have been inherited from surgical procedures and while they correctly predict SAVR outcomes, showing satisfying discrimination and calibration, they significantly overestimate TAVI mortality and adverse outcomes across all the surgical risk categories [4, 7]. Thus, there is a need for dedicated scores to assess periprocedural and long-term outcomes of TAVI patients.

In this issue of Kardiologia Polska (Kardiol Pol, Polish Heart Journal), Özdemir et al. reported the application of a multiparametric risk score, the InterMountain Risk Score (IMRS), to their cohort of TAVI patients, and they assessed its usefulness in predicting long-term mortality after the procedure [8]. The authors retrospectively enrolled a high-risk population of 133 patients who underwent TAVI in their center between 2010 and 2019. They stratified the patients according to death status and to IMRS values, classifying the patients into low, moderate, and high IMRS groups. The authors found that a high-risk class of IMRS was an independent predictor of long-term mortality in that population (adjusted hazard ratio [HR], $3.43,95 \%$ confidence interval [Cl], 1.54-7.65) They also reported at a median follow-up of 1433 days a good survival stratification according to IMRS and a more than double mortality in the high-class IMRS patients compared to the low IMRS group.

The IMRS is a multiparametric clinical risk score firstly developed and validated in 2009 to evaluate individual mortality using the complete blood count and metabolic profile of patients [9]. It was then updated in 2010 with the addition of red cell distribution width and other parameters such as albumin, bilirubin, and white cell differential count. Although not developed for TAVI patients, IMRS is a quick and easy-to-calculate risk score (with a freely available web tool) as it only requires data from common laboratory tests.

Özdemir et al. are the first to apply and evaluate the IMRS in TAVI patients, and they should be congratulated for their effort and their results, showing that a simple and clinical score, based on metabolic and nutritional factors, could be of help in predicting long-term mortality in TAVI patients and especially in identifying a high-risk category of patients in which the procedure may be futile because of sarcopenia, comorbidity, and nutritional status. These parameters are not commonly evaluated in the STS or EuroSCORE I and II risk scores.

Notably, several new TAVI risk models have been developed, but none is routinely 
used or included in ongoing trials mostly because of their complexity and poor accuracy that preclude broad generalization [10]. Accordingly, with the increasing impact of artificial intelligence (AI) in the cardiology field, a new risk score was able to show a good prediction of in-hospital mortality, with an Area Under Curve (AUC) of 0.92 [11, 12]. However, it has not been implemented in clinical practice yet and does not predict long-term mortality. Thus, the guidelines acknowledge the imperfect nature of risk scores and recommend that the decision to perform TAVI should be based on an evaluation by the multidisciplinary Heart Team and should be tailored to each patient on the basis of the functional and nutritive status to avoid futile procedures [1].

Future efforts are needed to develop TAVI dedicated risk scores to assess the risk of procedural complications (such as pacemaker implantation, paravalvular leak, stroke) and dedicated scores for valve-in-valve procedures [13-15].

In conclusion, a calculation with a simple tool like the IMRS before the TAVI procedure may be useful in predicting long-term mortality after TAVI and in evaluating the possible futility of the intervention. As underlined by the authors, larger scale and more comprehensive evaluations are needed to confirm the seminal findings of the present study that included only a limited number of high-risk patients from a single center and did not evaluate the accuracy of the IMRS.

\section{Article information}

Conflict of interest: None declared.

Open access: This article is available in open access under Creative Common Attribution-Non-Commercial-No Derivatives 4.0 International (CC BY-NC-ND 4.0) license, allowing to download articles and share them with others as long as they credit the authors and the publisher, but without permission to change them in any way or use them commercially. For commercial use, please contact the journal office at kardiologiapolska@ptkardio.pl.

How to cite: Conrotto F, Bruno F, D'Ascenzo F. TAVI and risk scores: Looking back while moving forward. Kardiol Pol. 2021; 79(11): 1193-1194, doi: 10.33963/KP.a2021.0155.

\section{REFERENCES}

1. Vahanian A, Beyersdorf F, PrazF, et al. 2021 ESC/EACTS Guidelines for the management of valvular heart disease. Eur Heart J. 2021 [Epub ahead of print], doi: 10.1093/eurheartj/ehab395, indexed in Pubmed: 34453165.

2. D'Ascenzo F, Bruno F, Baldetti $L$, et al. Aortic valve replacement vs. balloon-expandable and self-expandable transcatheter implantation: A network meta-analysis. Int J Cardiol. 2021; 337: 90-98, doi: 10.1016/j. ijcard.2021.04.068, indexed in Pubmed: 33974961.

3. Piroli F, Franchin L, Bruno F, et al. New advances in the prevention of transcatheter aortic valve implantation failure: current and future perspectives. Kardiol Pol. 2020; 78(9): 842-849, doi: 10.33963/KP.15522, indexed in Pubmed: 32692029.

4. D'Ascenzo F, Ballocca F, MorettiC, et al. Inaccuracy of available surgical risk scores to predict outcomes after transcatheter aortic valve replacement. J Cardiovasc Med (Hagerstown). 2013; 14(12): 894-898, doi: 10.2459/JCM. 0b013e3283638e26, indexed in Pubmed: 23877207.

5. Ferguson T, Dziuban S, EdwardsF, et al. The STS National Database: current changes and challenges for the new millennium. Ann Thorac Surg. 2000; 69(3): 680-691, doi: 10.1016/s0003-4975(99)01538-6.

6. Nashef SAM, Roques F, Sharples LD, et al. Risk factors and outcome in European cardiac surgery: analysis of the EuroSCORE multinational database of 19030 patients. Eur J Cardiothorac Surg. 1999; 15(6): 816-22; discussion 822, doi: 10.1016/s1010-7940(99)00106-2, indexed in Pubmed: 10431864.

7. Tarantini $G$, Nai Fovino L, Gersh BJ. Transcatheter aortic valve implantation in lower-risk patients: what is the perspective? Eur Heart J. 2018; 39(8): 658-666, doi: 10.1093/eurheartj/ehx489, indexed in Pubmed: 29020347.

8. Özdemir E, Esen S, Emren SV, et al. Association between Intermountain Risk Score and long-term mortality with the transcatheter aortic valve Implantation procedure. Kardiol Pol. 2021; 79(11): 1215-1222, doi: 10.33963/KP.a2021.0120, indexed in Pubmed: 34599498.

9. Horne BD, May HT, Kfoury AG, et al. The Intermountain Risk Score (including the red cell distribution width) predicts heart failure and other morbidity endpoints. Eur J Heart Fail. 2010; 12(11): 1203-1213.

10. D'Ascenzo F, Capodanno D, Tarantini $G$, et al. Usefulness and validation of the survival posT TAVI score for survival after transcatheter aortic valve implantation for aortic stenosis. Am J Cardiol. 2014; 114(12): 1867-1874, doi: 10.1016/j.amjcard.2014.09.031, indexed in Pubmed: 25438915.

11. Gallone G, Bruno F, D'Ascenzo F, et al. What will we ask to artificial intelligence for cardiovascular medicine in the next decade? Minerva Cardiol Angiol. 2021 [Epub ahead of print], doi: 10.23736/S2724-5683.21.05753-7, indexed in Pubmed: 34713677.

12. Hernandez-Suarez DF, Kim Y, Villablanca P, et al. Machine learning prediction models for in-hospital mortality after transcatheter aortic valve replacement. JACC Cardiovasc Interv. 2019; 12(14): 1328-1338, doi: 10.1016/j.jcin.2019.06.013, indexed in Pubmed: 31320027.

13. Bruno F, D'Ascenzo F, Vaira MP, et al. Predictors of pacemaker implantation after transcatheter aortic valve implantation according to kind of prosthesis and risk profile: a systematic review and contemporary meta-analysis. Eur Heart J Qual Care Clin Outcomes. 2021; 7(2): 143-153, doi: 10.1093/ehjqcco/qcaa089, indexed in Pubmed: 33289527.

14. Giordana F, Bruno F, Conrotto F, et al. Incidence, predictors and outcomes of valve-in-valve TAVI: A systematic review and meta-analysis. Int J Cardiol. 2020; 316: 64-69, doi: 10.1016/j.ijcard.2020.05.058, indexed in Pubmed: 32470529.

15. D'Ascenzo F, Salizzoni S, Saglietto A, et al. Incidence, predictors and cerebrovascular consequences of leaflet thrombosis after transcatheter aortic valve implantation: a systematic review and meta-analysis. Eur J Cardiothorac Surg. 2019; 56(3): 488-494, doi: 10.1093/ejcts/ezz099, indexed in Pubmed: 31321408. 